\title{
Three pediatric patients with primary hyperpara- thyroidism caused by parathyroid adenoma
}

\author{
Arum Oh", \\ Yena Lee', \\ Han-Wook Yoo', \\ Jin-Ho Choi ${ }^{2}$ \\ 'Department of Pediatrics, Chungbuk \\ National University Hospital, Chungbuk \\ National University College of Medicine, \\ Cheongju, Korea \\ ${ }^{2}$ Department of Pediatrics, Asan \\ Medical Center Children's Hospital, \\ University of Ulsan College of Medicine, \\ Seoul, Korea
}

Primary hyperparathyroidism (PHPT) is a hypercalcemia disorder with inappropriately normal or increased serum parathyroid hormone (PTH) levels resulting from excessive secretion of PTH from one or more of the parathyroid glands. PHPT is uncommon in infants and children, with an estimated incidence of 2-5 cases per 100,000 persons. Patients with PHPT usually present with bone pain, urolithiasis, or nephrolithiasis, as well as nonspecific symptoms such as fatigue and weakness. Asymptomatic hypercalcemia may also be detected incidentally. Only a few cases of pediatric PHPT have been reported in Korea. We present three patients (a 9-yearold girl, a 14-year-old boy, and a 14-year-old girl) with PHPT who manifested variable clinical features of hypercalcemia. The first and second patients each had a parathyroid adenoma and presented with abdominal pain caused by pancreatitis and a ureter stone, respectively. The third patient had an ectopic mediastinal parathyroid adenoma and presented with gait disturbance and weakness of the lower extremities. All of the patients underwent surgical resection of parathyroid adenoma, and their serum calcium levels subsequently normalized without medication.

Keywords: Hypercalcemia, Hyperparathyroidism, Parathyroid adenoma

\section{Highlights}

Primary hyperparathyroidism is a very rare in children. We experienced 3 patients with hypercalcemia caused by parathyroid adenoma. The calcium levels were decreased to normal after surgical resection.

\section{Introduction}

Parathyroid hormone (PTH) consists of 84 amino acids and is synthesized and released by the chief cells of the parathyroid glands. It plays an important role in regulating calcium levels and bone homeostasis. ${ }^{1)}$ PTH secretion is regulated by extracellular ionized calcium concentration. In other words, PTH secretion is stimulated by hypocalcemia and suppressed by increased ionized calcium through interaction with calcium-sensing receptors. Thus, PTH increases serum calcium level by raising calcium reabsorption in the renal proximal tubules and increasing calcium resorption from bone. ${ }^{1)}$ PTH stimulates the conversion of 25-hydroxyvitamin $\mathrm{D} 3\left(25(\mathrm{OH}) \mathrm{D}_{3}\right)$ to 1,25 -dihydroxyvitamin $\mathrm{D} 3\left(1,25(\mathrm{OH})_{2} \mathrm{D}_{3}\right)$ in the kidney, which in turn augments intestinal calcium absorption. In addition, PTH increases urinary phosphate excretion by stimulating fibroblast growth factor 23 release from mature osteoblasts and osteocytes. ${ }^{2}$

Primary hyperparathyroidism (PHPT) is defined as hypercalcemia with inappropriately normal or increased serum PTH levels resulting from excessive secretion of PTH from the parathyroid glands. The annual incidence of PHPT is estimated to be 3/10,000 in adults
Received: 18 December, 2020

Revised: 22 March, 2021

Address for correspondence:

Jin-Ho Choi

Department of Pediatrics, Asan Medical Center Children's Hospital, University of Ulsan College of Medicine, 88 Olympic-ro 43-gil, Songpa-gu, Seoul 05505, Korea Email:jhc@amc.seoul.kr https://orcid.org/0000-0003-11967826 
between the ages of 50 and 60 years, and it is 2 to 3 times more prevalent among women than men. ${ }^{3)}$ In contrast, PHPT is relatively uncommon in pediatric patients, with an estimated incidence of 2-5 cases per 100,000 persons, regardless of sex. A single benign parathyroid adenoma is the most common cause of PHPT in the general population, including children and adolescents. ${ }^{4)}$ PHPT is often associated with rare genetic disorders such as multiple endocrine neoplasia (MEN) 1 and 2A and familial hypocalciuric hypercalcemia. ${ }^{5}$

PHPT may be detected incidentally as asymptomatic hypercalcemia during routine laboratory testing; however, children have a tendency to present with hypercalcemic symptoms, such as bone pain, urolithiasis, nephrolithiasis, or nonspecific symptoms like fatigue and muscle weakness. ${ }^{5}$ Depression, anxiety, and difficulty with memory and concentration are frequently observed in patients with PHPT. Nevertheless, the pathogenesis of these symptoms in hyperparathyroidism remains unclear.

Measuring serum calcium and PTH is helpful for diagnosing PHPT. Tests to localize parathyroid adenomas include ultrasonography (US), computed tomography (CT), magnetic resonance imaging (MRI), and Tc-99m sestamibi parathyroid scans. Familial hypocalciuric hypercalcemia should be differentiated from parathyroid adenoma because the former generally requires no specific treatment. In patients with PHPT, focused parathyroidectomy to remove parathyroid adenomas is the treatment of choice and normalizes serum calcium levels.

Only a few cases of pediatric PHPT have been reported in Korea, and these patients underwent focused parathyroidectomy. ${ }^{6}$ We recently encountered 3 pediatric patients with PHPT caused by a single parathyroid adenoma with diverse clinical presentations.

\section{Case reports}

\section{Case 1}

A 9-year-old girl presented with recurrent abdominal pain, vomiting, and nausea. She was born at 40 weeks of gestation by normal spontaneous vaginal delivery with a birth weight of 2.9 $\mathrm{kg}$. From the age of 7 years, she had suffered from periumbilical pain, generalized weakness, and recurrent vomiting. After the age of 9 years, her symptoms occurred more frequently, and she was referred to our institution. The patient's height was $129 \mathrm{~cm}$ (Korean standard deviation score [SDS] of -0.67), and weight was $22.3 \mathrm{~kg}(-1.88 \mathrm{SDS})$. Her vital signs were as follows: blood pressure, 123/74 $\mathrm{mmHg}$; pulse rate, $112 \mathrm{bpm}$; and respiratory rate, 22 times/min. Electrocardiogram (EKG) demonstrated normal sinus rhythm. Biochemical findings showed an increased serum calcium level of $14.6 \mathrm{mg} / \mathrm{dL}$ (normal range, $8.6-10.2 \mathrm{mg} / \mathrm{dL}$ ) and serum ionized calcium level of 7.2 $\mathrm{mg} / \mathrm{dL}$ (normal range, $3.9-4.5 \mathrm{mg} / \mathrm{dL}$ ), as well as a low serum phosphorus level of $1.9 \mathrm{mg} / \mathrm{dL}$ (normal range, $2.5-4.5 \mathrm{mg} / \mathrm{dL}$ ). Serum intact PTH level was $514 \mathrm{pg} / \mathrm{mL}$ (normal range, 10-65 $\mathrm{pg} / \mathrm{mL}$ ), serum $25(\mathrm{OH}) \mathrm{D}_{3}$ level was $8.9 \mathrm{ng} / \mathrm{mL}$ (normal range, 30-100 ng/mL), and alkaline phosphatase (ALP) level was $220 \mathrm{IU} / \mathrm{L}$ (normal range, 81-316 IU/L). Spot urine calcium/ creatinine ratio was increased to $2,244 \mathrm{mg} / \mathrm{g}$ (normal range, $16.5-144 \mathrm{mg} / \mathrm{g})$. Her serum amylase and lipase levels were 919 $\mathrm{U} / \mathrm{L}$ (normal range, 30-110 U/L) and 1,650 U/L (normal range,

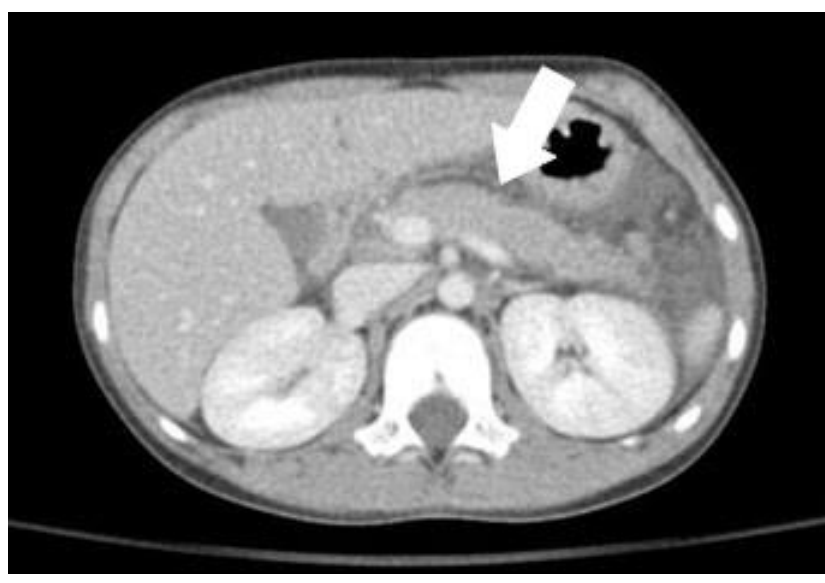

Fig. 1. Abdominal computerized tomography of subject 1. Mild pancreatic swelling (arrow) and subtle decrease in pancreatic tail density indicates interstitial edematous pancreatitis.

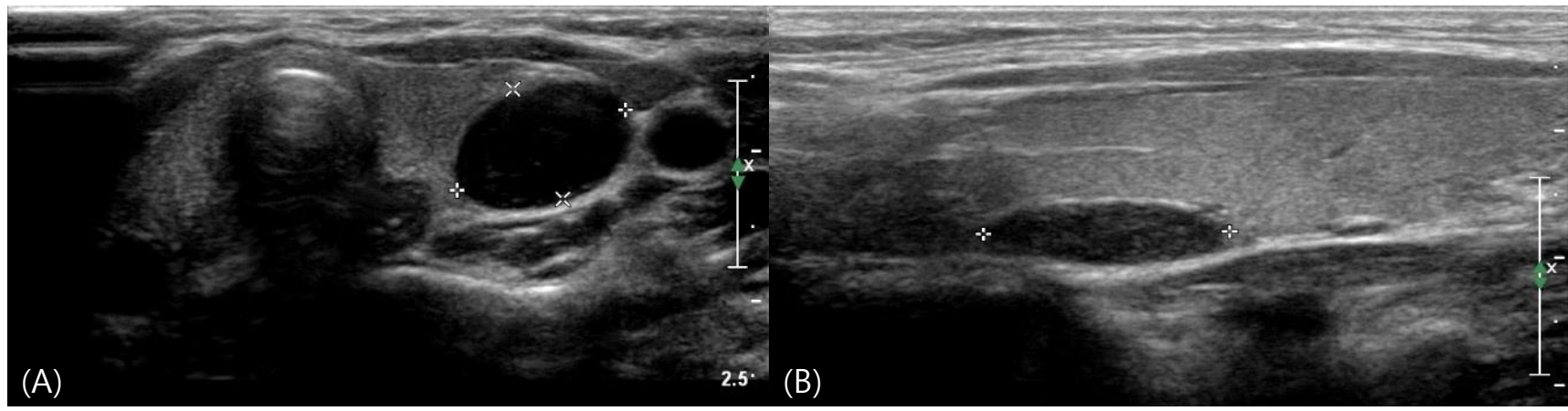

Fig. 2. Parathyroid ultrasonography (US) of subjects 1 and 2. (A) Parathyroid US of subject 1 revealed a well-defined $1.25 \times 0.81 \times 2.20-\mathrm{cm}$-sized hypoechoic mass in the lower pole in the posterior aspect of the left thyroid gland. (B) Parathyroid US of subject 2 showed a $1.5 \times 0.5 \times 1.6$-cm-sized nodule with increased vascularity in the upper pole in the posterior aspect of the right thyroid gland, suggesting parathyroid adenoma. 
13-60 U/L), respectively. Abdominal CT revealed pancreatic swelling and decreased density of the pancreatic tail, indicating interstitial edematous pancreatitis (Fig. 1). Serum amylase and lipase levels decreased gradually after intravenous (IV) hydration and fasting for treatment of pancreatitis. However, hypercalcemia was not improved by hydration, furosemide, IV hydrocortisone, or IV pamidronate. On the fifth day of hospitalization, she underwent hemodialysis for 2 days, which reduced the serum calcium level to $9.6 \mathrm{mg} / \mathrm{dL}$, but it increased again 2 days later. She had no family history of MEN. Molecular analysis of the CASR and MEN1 genes did not identify any mutation. A Tc-99m sestamibi parathyroid scan did not identify any parathyroid abnormalities; however, parathyroid US revealed a $1.3 \times 0.8 \times 2.2$-cm-sized, well-defined hypoechoic mass at the posterior of the left thyroid gland in the mid to lower pole, suggesting a parathyroid adenoma (Fig. 2A). She subsequently underwent surgical excision of parathyroid adenoma. A few hours after surgery, she experienced hypocalcemic tetany with a serum calcium level of $6.7 \mathrm{mg} / \mathrm{dL}$ and was treated with oral calcium carbonate (elemental calcium $75 \mathrm{mg} / \mathrm{kg} /$ day) and cholecalciferol (1,200 IU/day). Following treatment with medication for one month, serum calcium level was maintained between 9 and $10 \mathrm{mg} / \mathrm{dL}$ without any medication. She showed a normal growth rate of $6.4 \mathrm{~cm} / \mathrm{yr}$, and reached final adult height of $154 \mathrm{~cm}$ (10th-25th percentile; midparental height, $155 \mathrm{~cm})$.

\section{Case 2}

A 14-year-old girl presented with sudden left flank pain. She was born at term by cesarean section with birth weight of $2.6 \mathrm{~kg}$.
The patient's height and weight were $160 \mathrm{~cm}(0.14$ SDS), and 60 $\mathrm{kg}(0.96$ SDS), respectively. Her vital signs were as follows: blood pressure, 120/75 mmHg; pulse rate, $109 \mathrm{bpm}$; and respiratory rate, 20 times/min. EKG result was normal sinus rhythm. Initial serum calcium, phosphorus, and ionized calcium levels were $12.1 \mathrm{mg} / \mathrm{dL}, 3.4 \mathrm{mg} / \mathrm{dL}$, and $6.38 \mathrm{mg} / \mathrm{dL}$, respectively. Urine calcium/creatinine ratio was $103 \mathrm{mg} / \mathrm{g}$. Serum intact PTH level was elevated to $144 \mathrm{pg} / \mathrm{mL}$, serum $25(\mathrm{OH}) \mathrm{D}_{3}$ level was $8.2 \mathrm{ng} /$ $\mathrm{mL}$, and ALP level was $405 \mathrm{IU} / \mathrm{L}$. She had no specific family history of MEN. There were no rare sequence variants in the CASR gene. Abdomino-pelvic CT revealed a 6.3×5.6-mm-sized stone in the left ureter with obstructive nephropathy. A Tc$99 \mathrm{~m}$ sestamibi parathyroid scan detected a parathyroid mass at the upper pole in the posterior aspect of the right thyroid lobe. Parathyroid US also revealed a $1.5 \times 0.5 \times 1.6-\mathrm{cm}$-sized nodule with increased vascularity in the upper pole in the posterior aspect of the right thyroid gland (Fig. 2B). Extracorporeal shock-wave lithotripsy was performed for the left ureter stone. The patient underwent surgical excision of the parathyroid mass, and the pathological findings demonstrated parathyroid adenoma. Three days after surgery, calcium carbonate (elemental calcium $10 \mathrm{mg} / \mathrm{kg} /$ day $)$ and calcitriol $(0.75 \mu \mathrm{g} /$ day $)$ were given for transient hypocalcemia; however, the patient's serum calcium level returned to normal 7 days after surgery without further medication.

\section{Case 3}

A 14-year-old boy manifested difficulty walking for 2 years, which progressed to weakness in the lower extremities. The

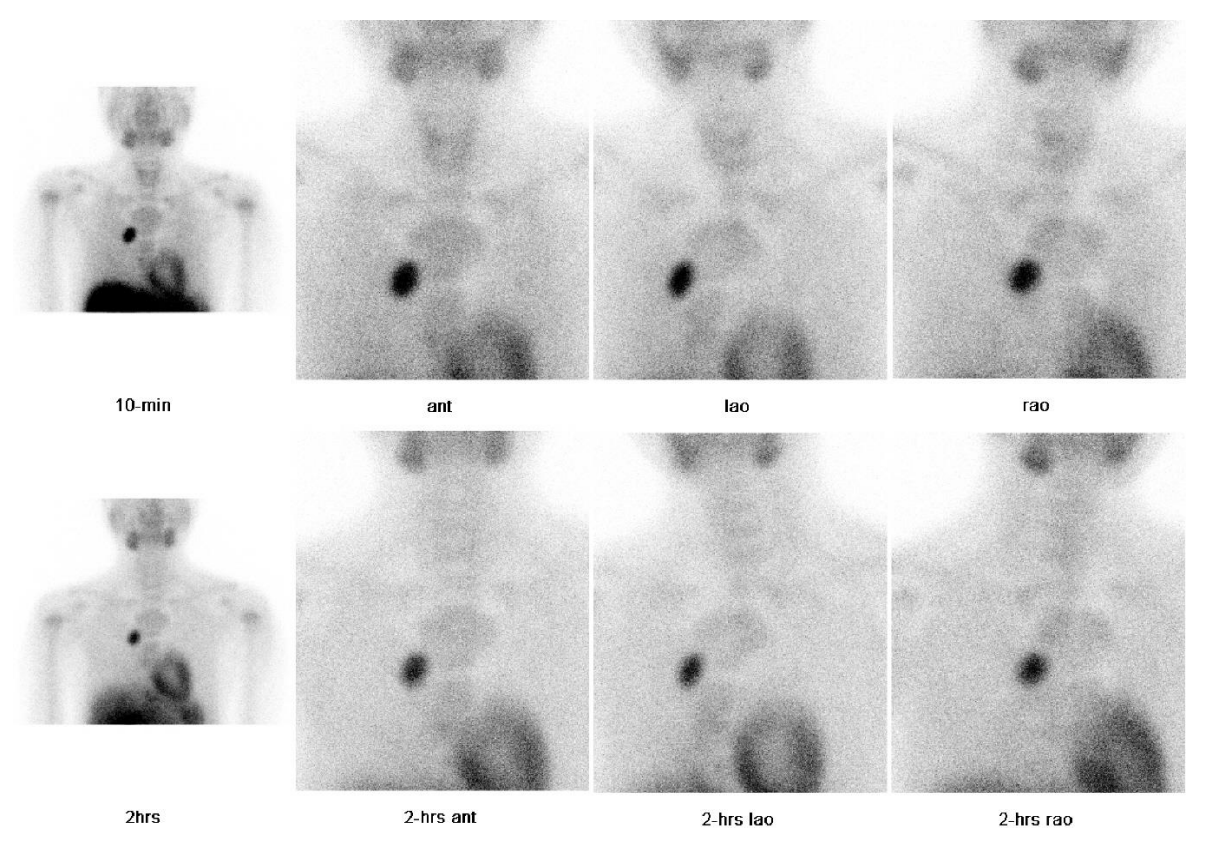

Fig. 3. Parathyroid positron emission tomography-computed tomography (PET/CT) of subject 3. In the 10-minute and 2-hour regional images and PET/CT images, there is a mass showing local uptake on the right side of the anterior mediastinum. 
patient's height and weight were $174.4 \mathrm{~cm}$ (1.41 SDS) and 59.2 $\mathrm{kg}(0.27$ SDS), respectively. His vital signs were as follows: blood pressure, 110/70 $\mathrm{mmHg}$; pulse rate, $94 \mathrm{bpm}$; and respiratory rate, 20 times/min. EKG demonstrated normal sinus rhythm. Initial serum calcium, phosphorus, and ALP levels were 11.2 $\mathrm{mg} / \mathrm{dL}, 3.1 \mathrm{mg} / \mathrm{dL}$, and 1,886 IU/L, respectively. Serum intact PTH level was $2984 \mathrm{pg} / \mathrm{mL}$. Serum $25(\mathrm{OH}) \mathrm{D}_{3}$ and $1,25(\mathrm{OH})_{2} \mathrm{D}_{3}$ levels were $4.6 \mathrm{ng} / \mathrm{mL}$ and $69.8 \mathrm{pg} / \mathrm{mL}$ (normal range, 15-90 $\mathrm{pg} / \mathrm{mL}$ ), respectively. He had no specific family history of MEN. Contrast-enhanced CT and parathyroid Tc-99m sestamibi positron emission tomography (PET)-CT showed a $2.6 \times 3.1-\mathrm{cm}$-sized homogeneously enhancing mass in the anterior mediastinum, abutting the ascending aorta (Figs. 3, 4). Bone mineral density $z$-scores of the L-spine and the femur neck were $-0.69\left(0.661 \mathrm{~g} / \mathrm{cm}^{2}\right)$ and $-1.94\left(0.452 \mathrm{~g} / \mathrm{cm}^{2}\right)$, respectively, according to age- and sex-matched Korean references.

MRI of the pelvis to evaluate lower extremity weakness demonstrated a wide sacroiliac joint space and posterior and inferior displacement of the proximal femoral epiphysis with irregular metaphysis and joint erosion, indicating a bilateral slipped capital femoral epiphysis (SCFE). The patient underwent excision of the ectopic parathyroid adenoma, and calcium carbonate (elemental calcium $40 \mathrm{mg} / \mathrm{kg} /$ day) and alfacalcidiol (2 $\mu \mathrm{g} /$ day) were given for one month after surgery. However, intact PTH level was $310 \mathrm{pg} / \mathrm{mL}$ with low calcium $(7.7 \mathrm{mg} / \mathrm{dL})$ and $25(\mathrm{OH}) \mathrm{D}_{3}(6.6 \mathrm{ng} / \mathrm{mL})$, and normal ALP (203 IU/L). Biannual blood tests and parathyroid PET-CT were scheduled to monitor intact PTH and calcium levels.

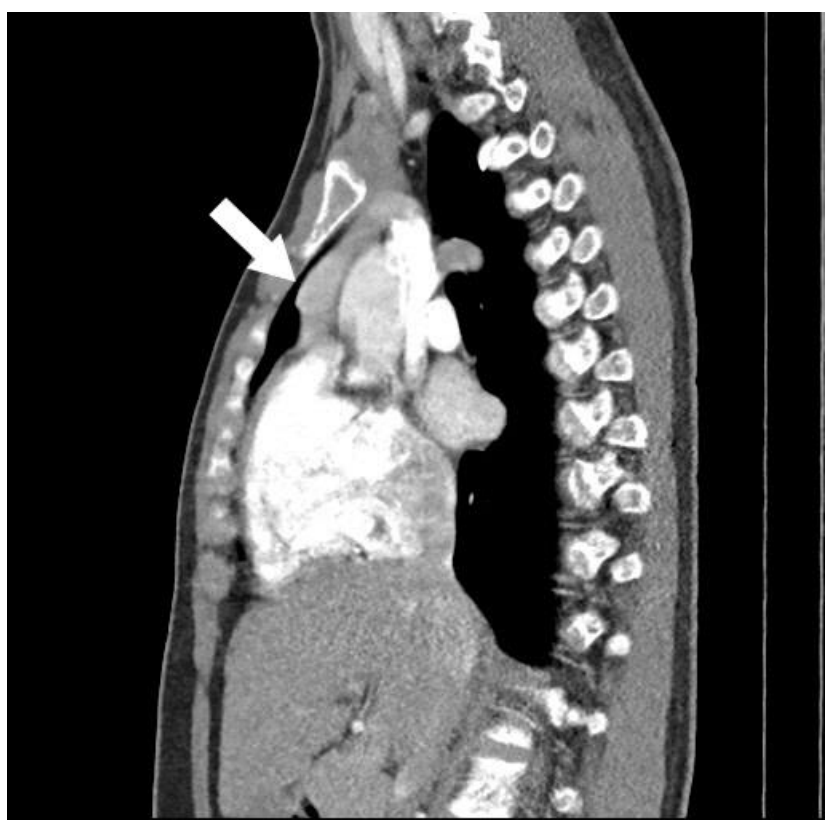

Fig. 4. Contrast-enhanced computed tomography of the chest of subject 3 showing a $2.6 \times 3.1-\mathrm{cm}$-sized, homogeneously enhancing mass in the anterior mediastinum (arrow), abutting to the ascending aorta, suggesting parathyroid adenoma.

\section{Discussion}

This study describes 3 pediatric patients with PHPT who presented with hypercalcemia. A single parathyroid adenoma was found in 2 patients, while the other had an ectopic mediastinal parathyroid adenoma, which is rare and found in only $10 \%$ of pediatric PHPT cases. Surgical excision of parathyroid adenoma was performed in all patients, and their serum calcium levels were subsequently restored to the normal range without medication.

For localization of parathyroid adenomas, noninvasive imaging tools such as US, CT, MRI, and Tc-99m sestamibi parathyroid scans are generally used. One meta-analysis reported that the sensitivity of high-resolution US was 78\% in comparison to $88 \%$ for dual-phase Tc- $99 \mathrm{~m}$ sestamibi scintigraphy. ${ }^{8)}$ However, Tc-99m sestamibi parathyroid imaging has a limited capacity to detect small parathyroid adenomas or multiglandular lesions, especially in the case of preoperative normocalcemia. ${ }^{9)}$ Accordingly, a combination of different imaging modalities is required. Combined US and Tc-99m sestamibi scintigraphy have shown high sensitivity of up to 94.5\% for preoperative localization of parathyroid adenomas. ${ }^{10)}$

PHPT is usually symptomatic in young patients, except for a few young children in whom asymptomatic hypercalcemia is detected incidentally. Nephrolithiasis, nephrocalcinosis, and bone pain are the most common clinical features in pediatric patients with PHPT. Pediatric patients have a tendency to present with hypercalcemic symptoms compared to adults. ${ }^{11)}$ There is a hypothesis that this may be caused by delayed diagnosis. Unlike most adults who have hyperparathyroidism on routine blood screening, children rarely undergo blood screening, so it is possible that late detection may affect symptoms. ${ }^{12)}$ In addition, the clinical symptoms of children are different from those of adults. For example, bone pain and rickets are common in children and adolescents, while renal stones are generally found in adults. ${ }^{13)}$

The prevalence of acute pancreatitis in PHPT is between 1.5\% and $13 \% .{ }^{14)}$ The association between PHPT and pancreatitis remain unclear. Notwithstanding, a previous report suggested that the frequency of pancreatitis among patients with PHPT was about 30-fold higher than among the general population. ${ }^{15)}$ Symptoms of pancreatitis improve after surgical treatment in most patients with PHPT. Recently, some experimental evidence suggested that hypercalcemia may cause intrapancreatic trypsin activation and pancreatic damage, which can lead to pancreatitis. $^{16)}$

SCFE is associated with PHPT, although the frequency is low. PHPT is an unusual cause of SCFE, with only 11 cases having been reported. ${ }^{17)}$ PTH receptors are present in the hypertrophic cartilage zone of the epiphyseal plate. This is the same zone where SCFE occurs. It is possible that the action of PTH on growth plate chondrocytes results in the aberrant cartilage mineralization through its mediators and metalloproteinases, which can extend the duration required for fusion of the epiphyseal plate. ${ }^{18)}$ Prolonged elevation of PTH levels result in 
bone catabolism by elevation of receptor activator of nuclear factor kappa beta (RANKL) and reduction of osteoprotegrin (OPG) levels. Children have higher concentrations of bone biomarkers and faster bone turnover than adults. ${ }^{19)}$ Thus, the bone remodeling cycle, which protects the integrity of bone from micro-damage during daily life, is shorter. ${ }^{20)}$

In conclusion, this study described 3 pediatric patients with PHPT, which is relatively rare in children and adolescents. Although the clinical features of hypercalcemia are nonspecific and diverse, PTHP should be considered in patients with gastrointestinal symptoms, flank pain, limping, and hip pain. Clinicians should be aware of the various clinical presentations of hypercalcemia in children, as prompt diagnosis is essential to preventing complications of hypercalcemia.

\section{Ethical statement}

This study was approved by the Institutional Review Board of Asan Medical Center, Seoul, Korea (IRB No. 2019-0880). Informed consent was obtained from all individual participants included in the study and their parents.

\section{Notes}

Conflicts of interest: No potential conflict of interest relevant to this article was reported.

Funding: This study was supported by the National Research Foundation (NRF) of Korea funded by the Korea government (Ministry of Science and ICT) (No. NRF2021R1F1A104593011).

Author contribution: Conceptualization: HY, JC; Data curation: HY, JC; Formal analysis: YL; Funding acquisition: JC, Writing - original draft: AO; Writing - review \& editing: AO

\section{ORCID}

Arum Oh: 0000-0001-6848-5954

Yena Lee: 0000-0001-8740-8049

Han-Wook Yoo: 0000-0001-8615-186X

Jin-Ho Choi: 0000-0003-1196-7826

\section{References}

1. Akerstrom G, Hellman P, Hessman O, Segersten U, Westin G. Parathyroid glands in calcium regulation and human disease. Ann N Y Acad Sci 2005;1040:53-8.

2. Goltzman D, Mannstadt M, Marcocci C. Physiology of the calcium-parathyroid hormone-vitamin D axis. Front Horm Res 2018;50:1-13.

3. Griebeler ML, Kearns AE, Ryu E, Hathcock MA, Melton LJ 3rd, Wermers RA. Secular trends in the incidence of primary hyperparathyroidism over five decades (19652010). Bone 2015;73:1-7.

4. Khan AA, Hanley DA, Rizzoli R, Bollerslev J, Young JE, Rejnmark L, et al. Primary hyperparathyroidism: review and recommendations on evaluation, diagnosis, and management. A Canadian and international consensus. Osteoporos Int 2017;28:1-19.

5. Stack BC, Bodenner D, editors. Medical and surgical treatment of parathyroid diseases: an evidence-based approach. Cham (Switzerland): Springer International Publishing, 2017:593-604.

6. Park WH, Bae BJ, Choi SO. Primary hyperparathyroidism due to parathyroid adenoma. J Korean Assoc Pediatr Surg 2000;6:68-9.

7. Kang MJ, Hong HS, Chung SJ, Lee YA, Shin CH, Yang SW. Body composition and bone density reference data for Korean children, adolescents, and young adults according to age and sex: results of the 2009-2010 Korean National Health and Nutrition Examination Survey (KNHANES). J Bone Miner Metab 2016;34:429-39.

8. Ruda JM, Hollenbeak CS, Stack BC Jr. A systematic review of the diagnosis and treatment of primary hyperparathyroidism from 1995 to 2003. Otolaryngol Head Neck Surg 2005;132:359-72.

9. Merlino JI, Ko K, Minotti A, McHenry CR. The false negative technetium-99m-sestamibi scan in patients with primary hyperparathyroidism: correlation with clinical factors and operative findings. Am Surg 2003;69:225-9; discussion 229-30.

10. Lumachi F, Zucchetta P, Marzola MC, Boccagni P, Angelini F, Bui F, et al. Advantages of combined technetium-99msestamibi scintigraphy and high-resolution ultrasonography in parathyroid localization: comparative study in 91 patients with primary hyperparathyroidism. Eur J Endocrinol 2000;143:755-60.

11. Boggs E, Szymusiak J. Common in adults and often overlooked in pediatrics: primary hyperparathyroidism in an adolescent patient. Pediatrics 2018;141:490.

12. Vanstone MB, Udelsman RD, Cheng DW, Carpenter TO. Rapid correction of bone mass after parathyroidectomy in an adolescent with primary hyperparathyroidism. J Clin Endocrinol Metab 2011;96:E347-50.

13. Shah VN, Bhadada SK, Bhansali A, Behera A, Mittal BR, Bhavin V. Influence of age and gender on presentation of symptomatic primary hyperparathyroidism. J Postgrad Med 2012;58:107-11

14. Misgar RA, Mathew V, Pandit K, Chowdhury S. Primary hyperparathyroidism presenting as recurrent acute pancreatitis: a case report and review of literature. Indian J Endocrinol Metab 2011;15:54-6.

15. Bai HX, Giefer M, Patel M, Orabi AI, Husain SZ. The association of primary hyperparathyroidism with pancreatitis. J Clin Gastroenterol 2012;46:656-61.

16. Mithöfer K, Fernández-Del Castillo C, Frick TW, Lewandrowski KB, Rattner DW, Warshaw AL. Acute hypercalcemia causes acute pancreatitis and ectopic trypsinogen activation in the rat. Gastroenterology 1995;109:239-46.

17. Alghamdi AA, Ahmad MM, Almalki MH. Slipped capital femoral epiphysis and primary hyperparathyroidism: a case report. Clin Med Insights Endocrinol Diabetes 2016;9:73- 
76.

18. Papavasiliou KA, Kapetanos GA, Kirkos JM, Beslikas TA, Dimitriadou AS, Papavasiliou VA. The pathogenetic influence of i-parathyroid hormone on slipped capital femoral epiphysis. Towards a new etiologic approach? J Musculoskelet Neuronal Interact 2003;3:251-7.
19. Eapen E, Grey V, Don-Wauchope A, Atkinson SA. Bone health in childhood: usefulness of biochemical biomarkers. EJIFCC 2008; 19:123-36.

20. Eriksen EF. Cellular mechanisms of bone remodeling. Rev Endocr Metab Disord 2010;11:219-27. 